\title{
DOI 10.18699/BGRS/SB-2020-194 \\ Flowering patterns of herbaceous multi-flowered monocarpic shoots of Campanula sarmatica
}

\author{
Eduard Fomin \\ Systems Biology Department \\ Institute of Cytology and Genetics SB RAS \\ Novosibirsk, Russia \\ fomin@bionet.nsc.ru
}

\author{
Tatyana Fomina \\ Laboratory of introduction of ornamental plants \\ Central Siberian Botanical Garden SB RAS \\ Novosibirsk, Russia \\ 0000-0003-4724-2480
}

\begin{abstract}
Flowering analysis of Campanula sarmatica, Campanulaceae family at the level of individual shoots was performed. It has been established that the flowering curves of C. sarmatica shoots are bimodal. The first peak corresponds to the flowering of the main axis, and the second to the lateral axes of the inflorescence. Flowering curves have noticeable individual differences in the heights of the main peaks, due to the difference in the number of flowers on the main axis and lateral axes on different shoots. The found mechanism of the formation of the curves makes it possible to extract the type of inflorescence (botryoid or panicle) and estimate the number of lateral axes directly from the flowering curve for any observed shoot.
\end{abstract}

Keywords - flowering patterns, flowering model, monocarpic shoot, Campanula sarmatica, inflorescence, ornamental plants

\section{Introduction}

The main component of the reproductive success of a plant in its seasonal development is the synchrony with flowering and environmental conditions favorable for fertilization and seed setting. For plants with multi-flowered inflorescences, another important component of reproduction efficacy is the arrangement of flowers on the shoot and the sequence of their opening [1]. The evolutionary mechanisms underlying the formation of flowering patterns may be different. Most scientists interpret the observed flowering regularities as a trait of adaptation to the totality of abiotic and biotic factors evolved in intra- and interspecific competition [2]. Heterogeneous environment, climatic changes, and the seasonal activity of pollinators and phytophages injuring generative organs are considered determiners of the optimum flowering time. Also, the entrance to the generative phase of the seasonal cycle is influenced by vegetative growth parameters [3].

Studies of flowering at the organ, organismal, populational, or plant cenotic levels pursue different goals and employ different methods [4]. One of the approaches to plant development description involves phenological curves, which represent the time variations of certain traits. Flowering curves have gained the greatest acceptance. They reflect the start, mean date, maximum, duration, flowers opening synchrony, and asymmetry, and these parameters are phylogenetically contingent [5]. Most models applied to various plant taxa and life forms describe their phenology, including flowering, at the population level $[6,7]$.

The classical study [8] mentions that scientists give insufficient attention to the modeling of individual flowering. Although the environmental conditions modulate flowering timing [9], flowering phenology is determined primarily by genetic (physiological) factors, thus demanding research at the organismal level [6]. The phenology of flowering an individual plant is not the mere sum over its individual flowers; rather, it is determined by regulatory mechanisms more complicated than at the organ level and by more intricate ecological relationships. If only because of the longer duration of the process, it is substantially influenced by the populational and cenotic interactions with pollinators and phytophages [3]. The attention to flowering modeling at the organismal level is also associated with the recent advance of automated phenotyping systems based on pattern recognition $[10,11]$. Here we use the new nonparametric computational model proposed by us earlier [12] to describe the flowering of individual shoots, individual plants or their groups in multiflorous species. The model can be regarded as datadriven statistical and/or instance-based. All structural and dynamic relationships in the model are numerically obtained by accumulation and integration of available observations, and these relationships are automatically rebuilt as soon as more data is added.

\section{Materials and methods}

The model was tested on Georgian bellflower (Campanula sarmatica Ker-Gawl.) from the collection of ornamental plants of natural flora, Central Siberian Botanical Garden, Novosibirsk $\left(54^{\circ} 49^{\prime} 15.0^{\prime \prime} \mathrm{N} 83^{\circ} 06^{\prime} 16.1^{\prime \prime} \mathrm{E}\right)$. This species is an herbaceous polycarpic, which holds promise as a long-living perennial with lovely flowers [13]. It annually forms 36-90 $\mathrm{cm}$ high reproductive shoots bearing $15-73-\mathrm{cm}$ terminal inflorescences. The inflorescence is a one-sided leafy-bracted botryoid or panicle with $2^{\text {nd }}$ order lateral axes, bearing 6 to 25 flowers. The terminal flower on the main axis always opens first, and is accompanied by three or four flowers in the lower third of the inflorescence, and subsequent flowers open in a divergent way. Two to six flowers develop on lateral axes, not necessarily starting from the terminal position. The longevity of one flower is two to four days, and the flowering of a shoot lasts for about 15 days.

Phenological observations were conducted throughout the flowering season, generally at three-day intervals. Phases of development - start (petal separation), opened flower, and end (corolla withering and browning) - were recorded for each flower on a shoot. The description of inflorescence structure followed modern work [14]. At the shoot level, flowering dynamics was traced according to the following phenological phases: start (opening of the first flower), complete flowering (about one-half of flowers open and first ovaries appear), and end (the last one or two flowers). The inflorescences were described at the end of the growth season on a sample of ten shoots for three years.

The data missed in the observations were reconstructed by averaging over a large sample of the most probable values generated by the maximum likelihood method [15]. All nonlinear regression functions were obtained by lowess smoothing [16]. The modeling was done with in-house software written in $\mathrm{C}++$ on the OS Linux platform. 


\section{Results}

To illustrate the model, we select three panicle-type observed shoots of C. sarmatica with increasingly complicated structures of their inflorescence. We show features of flowering on axes of various orders and how the complication of the structure modifies flowering curves. The fig. 1 demonstrate some of the detected dependencies. Data on axes of different orders are shown in different colors.

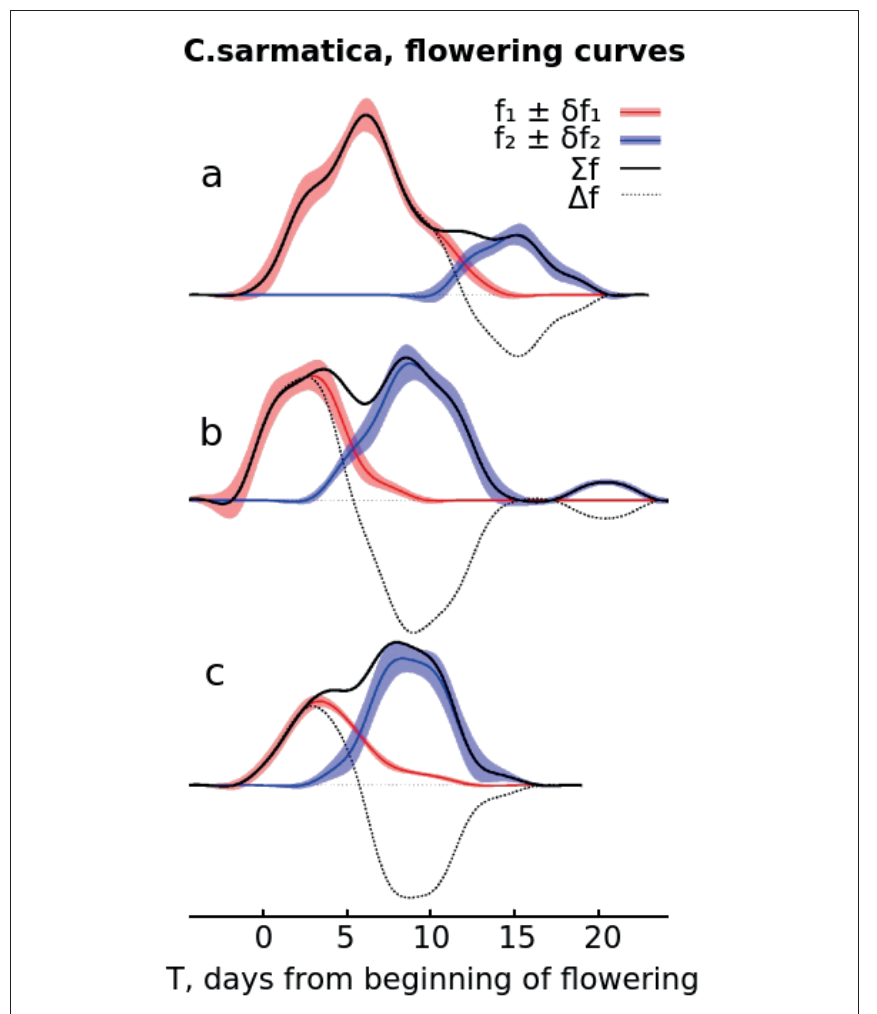

Fig. 1. Flowering curves for $1^{\text {st }}$ and $2^{\text {nd }}$ order axes with moving standard errors $\mathrm{f}_{\mathrm{i}} \pm \delta \mathrm{f}_{\mathrm{i}}$; the total $\Sigma \mathrm{f}$ and difference $\Delta \mathrm{f}$ flowering curves. The shoot with: (a) few $2^{\text {nd }}$ order flowers; (b) few $2^{\text {nd }}$ order axes; (c) many $2^{\text {nd }}$ order axes.

The flowering curves of observed shoots illustrate the following features of $C$. sarmatica flowering:

- The main axis and $2^{\text {nd }}$ order axes flower asynchronously and form a bimodal flowering curve.

- The shape of a flowering curve depends on the degree of inflorescence branching. The curve for one-sided leafybracted botryoid or for panicle with occasional $2^{\text {nd }}$ order flowers has a single peak. The curve for an inflorescence with few lateral axes and commensurable numbers of $1^{\text {st }}$ and $2^{\text {nd }}$ order flowers is bimodal.

- $\quad$ The flowering on $2^{\text {nd }}$ order axes starts when the $1^{\text {st }}$ order axis generally withers. The intervals between the peaks of flowering curves of different orders may vary among observed shoots.

\section{Discussion}

Using the new model, we confirmed the previously obtained results [15] that the flowering curve of individual C.sarmatica shoots is bimodal. The first peak reflects the opening of flowers on the main axis, and the second, on lateral axes of the inflorescence. Additionally, we found that the main variations in the flowering curve shape are determined by two factors: the degree of inflorescence branching and the time of transfer of flowering from the main axis to $2^{\text {nd }}$ order axes. The former factor determines the amplitudes of the major peaks, and the latter, the distance between them. Thereby, the flowering curve for a one-sided leafy-bracted botryoid and for panicle with occasional $2^{\text {nd }}$ order flowers has one peak, and for a panicle with advanced $2^{\text {nd }}$ order axes, two peaks, the height of the second peak is related to the number of the $2^{\text {nd }}$ order flowers. The latter makes it possible to extract the type of inflorescence (botryoid or panicle) and estimate the number of lateral axes directly from the flowering curve for any observed shoot. It should be mentioned that in the literature there are no examples of extracting any parameters of inflorescence from flowering curves, although the fact that the parameters of flowering curves are due phylogenetically was noted decades ago [5].

Thus, the new model does not only reproduce the natural variability of individual flowering and can be used to describe groups of individual plants in academic and applied research. The model allows us to discover new patterns of flowering, which expands our knowledge of the biology of individual flowering. They can be considered as phenotypic signs of plant life forms with multi-flowered inflorescences.

\section{References}

[1] Harder LD, Prusinkiewicz P. 2013. The interplay between inflorescence development and function as the crucible of architectural diversity. Annals of Botany 112:1477-1493.

[2] Snow DW. 1965. A possible selective factor in the evolution of fruiting seasons in tropical forest. Oikos 15:274-281.

[3] Ehrlén J. 2015.Selection on flowering time in a life-cycle context. Oikos 124(1):92-101.

[4] Davila-Velderrain J, Martinez-Garcia JC, Alvarez-Buylla ER. 2016. Dynamic network modelling to understanding flowering transition and floral patterning. Journal of Experimental Botany 67(9):2565-2572.

[5] Rathcke B., Lacey EP. 1985. Phenological patterns of terrestrial plants. Annual Review of Ecology and Systematics 16:179-214.

[6] Normand F, Habib R, Chadoeuf J. 2002. A stochastic flowering model describing an asynchronically flowering set of trees. Annals of Botany 90:405-415.

[7] Michalski SG, Durka W. 2007. Synchronous pulsed flowering: analysis of the flowering phenology in Juncus (Juncaceae). Annals of Botany 100(6):1271-1285.

[8] Primack RB. 1985. Patterns of flowering phenology in communities, populations, individuals, and single flowers. In: White J, eds. The Population Structure of Vegetation. Handbook of Vegetation Science, vol 3. Dordrecht: Springer, 571-593.

[9] Erwin J. 2007. Factors Affecting Flowering in Ornamental Plants. In: Anderson NO, eds. Flower Breeding and Genetics. Dordrecht: Springer, 7-48.

[10] Li L, Zhang Q, Huang D. 2014. A review of imaging techniques for plant phenotyping. Sensors 14(11):20078-20111.

[11] Carranza-Rojas J, Goeau H, Bonnet P, Mata-Montero E, Joly A. 2017. Going deeper in the automated identification of herbarium specimens. BMC Evolutionary Biology 17:181.

[12] Fomin ES, Fomina TI. 2020. "A nonparametric model for analysis of flowering patterns of herbaceous multi-flowered monocarpic shoots" unpublished.

[13] Fomina TI. 2012. Biological characteristics of ornamental plants of natural flora in West Siberia. Novosibirsk, In Russian

[14] Claßen-Bockhoff R, Bull-Hereñu K. 2013. Towards an ontogenetic understanding of inflorescence diversity. Annals of Botany 112:15231542.

[15] Fomin ES, Fomina TI. 2018. Patterns and models of flowering of some Campanulaceae Juss. species. Vavilov Journal of Genetics and Breeding. 22(7):845-855

[16] Cleveland WS. 1979. Robust Locally Weighted Regression and Smoothing Scatterplots. J Am Statistical Association 74(368): 829836. 